\title{
Least mean sixth control approach for three-phase three-wire grid-integrated PV system
}

\author{
Touheed Khan', Mohammed Asim², Mohammad Saood Manzar³, Md Ibrahim, Shaikh Sadaf Afzal \\ Ahmed $^{5}$ \\ ${ }^{1,2,4}$ Electrical Engineering Department, Integral University, Lucknow, India \\ ${ }^{3}$ Department of Environmental Engineering, Imam Abdul rahman Bin Faisal University, 31451 Dammam, Arab Saudi \\ ${ }^{5}$ Department of Computer Science, University of Mumbai, Konan Gayanpeeth College of Engineering, Maharahtra, India
}

\section{Article Info}

Article history:

Received Jul 19, 2021

Revised Sep 22, 2021

Accepted Sep 29, 2021

\section{Keywords:}

\section{D-STATCOM}

Least mean sixth control Maximum power point track Power quality PV array

\begin{abstract}
This work proposes an adaptive filter based on a new least mean sixth control approach with incremental conductance method of MPP for 3-phase gridincorporated photovoltaic (PV) system. The proposed system comprises a PV array, 3-phase DC to AC converter, maximum power point tracker (MPPT), three-phase electronic load, and a 3-phase grid. The combination of solar PV array and the voltage source converter (VSC) supplies power to the grid. The 3-phase inverter as a distribution static synchronous compensator (DSTATCOM) improves the quality of the system performance in case of zero solar irradiation. D-STATCOM also reduces total harmonic distortion (THD) in grid currents, improves power factor, and maintainsa constant voltage at the point of common coupling (PCC). The system modelling and simulation is achieved on MATLAB/Simulink. The proposed system performance has been found satisfactory and conform to IEEE-519 standards.
\end{abstract}

This is an open access article under the CC BY-SA license.

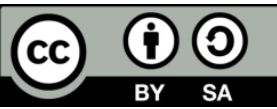

\section{Corresponding Author:}

Mohammed Asim

Department of Electrical Engineering

Integral University

Kursi Road, Lucknow, 226026 India

Email: asimamu@gmail.com

NOMENCLATURE

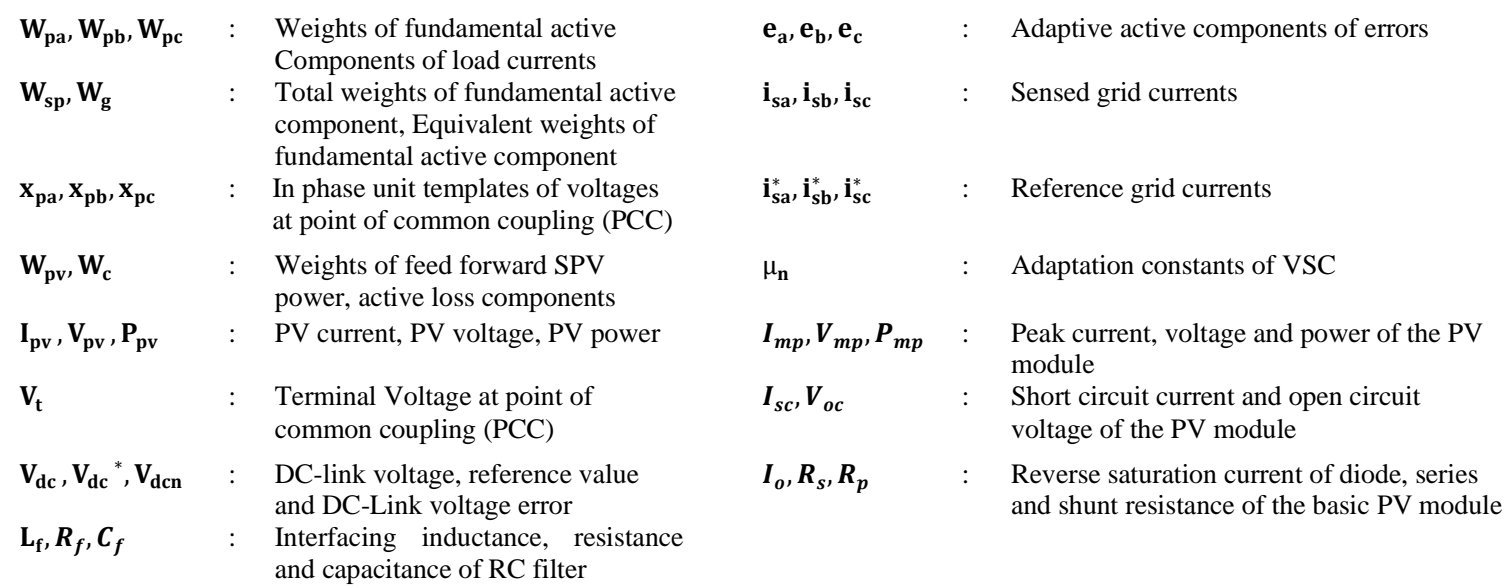




\section{INTRODUCTION}

Due to an increase in power electronics load, three-phase electrical distribution systems are facing serious power quality complications such as load unbalancing, high harmonic currents, more reactive power flow, and poor voltage regulation. Besides, higher penetration of renewable energy further affects the power supply quality, and thereby, voltage levels are adversely affected. Therefore, voltage regulation has become an issue of greater importance in grid integration [1]-[3]. The PV array, along with the D-STATCOM converts the DC into AC, improves the power quality by minimizing harmonic distortions, compensates the required reactive power, and maintain a balance of power in all phases of electrical system [4]. It is also exchanging real power when the DSTATCOM is provided with an external dc source [5]-[8]. A D-STATCOM requires an efficient control technique for robust operation and for what various control algorithms is used, which generates pulses for switches of inverter. These pulses are generated through a hysteresis current controller where sensed currents are compared with the reference currents [9]. The principal aim of the control is to meet the load demand by taking array power and to supply remaining power to the 3-phase grid. If the generated solar PV power is insufficient for load, extra required power can be taken from the network in order to meet the load demand. In addition, control algorithms also offer mitigation of power quality (PQ) problems such as harmonic filtering, reactive power compensation, load balancing, poor voltage regulation, and power factor correction [10], [11].

Numerous control algorithms are used for the efficient operation of D-STATCOM, such as synchronous rotating frame (SRF) control, instantaneous reactive power theory (IRPT), and adaptive based control algorithm. The dq0 transformation based SRF control is a most common algorithm as it performs quite well unity power factor operation [12], [13]. However, in this control technique, the second harmonic component is prevailing due to load unbalances causes performance slow down. So, a low pass filter is used for mitigating second-order harmonic components. Other traditional controls have more response time and slow convergence due to the complex block, including abc-dq transformation [14], [15].

Adaptive filter theory exposes its power to track the atmospheric changes and characteristics of the unknown system. The filter parameters are self-adjusted during the changing environmental conditions that the filter behavior and surrounding conditions are kept to serve its purpose [16]-[19]. There are various adaptive controls that have been developed and available in the literature, such as recursive least square (RLS), least mean square (LMS). Among all of them, the LMS and its variants are highly popular for their fast convergence speed and stability. It is a simple and fundamental adaptive filter based control on getting the desired result. The main function of LMS control is to extract accurate pulse and to minimize the error for the efficient operation of D-STATCOM. LMS control with D-STATCOM improves current related quality problems such as harmonics in grid currents, load balancing of non-linear load, voltage regulation. On the other hand, the drawbacks of the LMS method are that when excitation is not present at the input, this algorithm is failed to stabilize. As a result, it produces unbounded parameter estimation and error, which put down the system performance and create numerical problems. Moreover, because of the low input signal, the LMS control algorithm also experiences stalling. Therefore, a leakage factor is added to this algorithm to diminish stalling while stabilizing the system at the same time and to give fast convergence response [20]-[23]. The proposed system, along with the least mean sixth control and single-stage topology, shown in Figure 1 (a), Figure 1 (b) is showing the block diagram of the proposed control algorithm showing how the reference grid currents are generated and then the reference grid currents and the sensed grid currents are compared using hysteresis controller to gererate output gate pulses for the efficient switching of the inverter.

The proposed system provides several advantages over other topologies.

- The least mean sixth control algorithm is a modified form of LMS algorithm. It involves higher order (fifth) error term in the weight updating equation. Owing to higher-order optimization, the proposed control offers reduced mean square error (MSE) and thereby offering reduced THD and faster convergence rate.

- The least mean sixth control with the PV system offers lesser noise in their weights in comparison with the conventional LMS control.

- The system offers greater efficiency due to one stage converter topology [13], i.e., although double stage topology has the advantage of flexibility in controller designing, it also has some deficiencies. With more circuit stages, the power loss raises, this decreases the system efficiency. Moreover, more stages increase the complexity of the system and thereby reduce the reliability of the system. Thus, the one-stage topology has been used. 


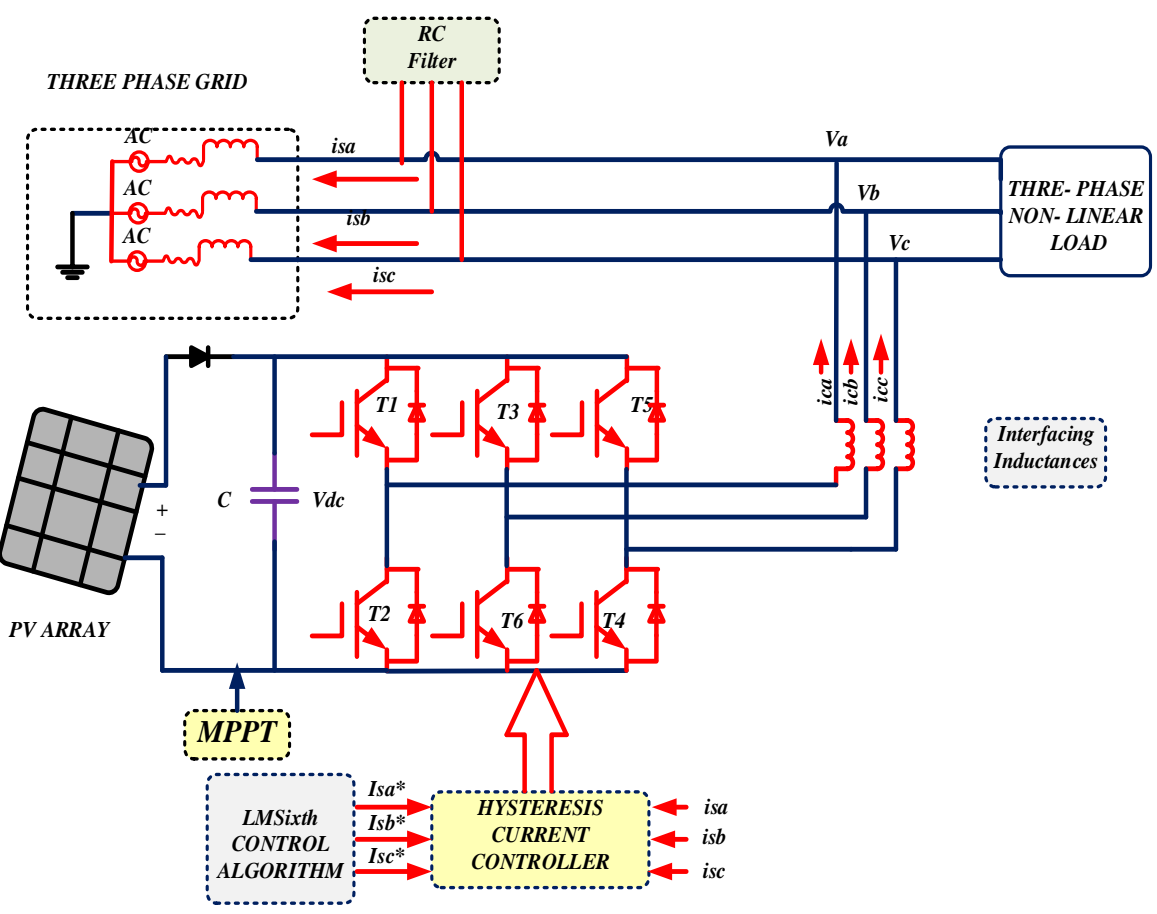

(a)

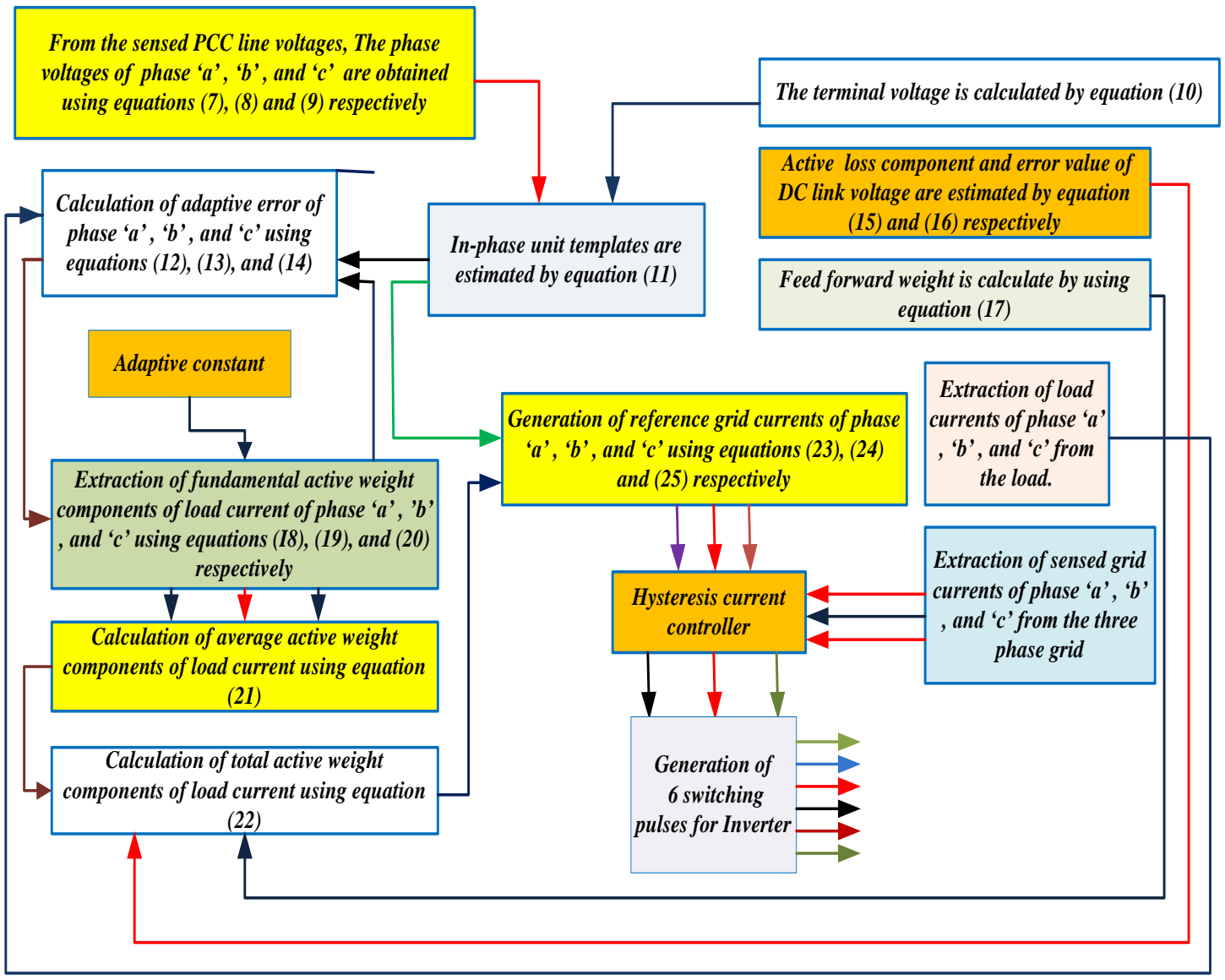

(b)

Figure 1. These figures are; (a) general block diagram of proposed system, (b) block diagram of the proposed least mean sixth control algorithm 


\section{SYSTEM MODELING}

\subsection{Modeling of $21 \mathrm{KW}$ PV array}

Here parameters of KC200GT PV array modeled at $[25]{ }^{\circ} \mathrm{C}$ and $1000 \mathrm{~W} / \mathrm{m}^{2}$ are taken as basic PV module [24], [25] shown in Table 1.

Table 1. Parameters of KC200GT PV array modeled at 『25』 ${ }^{\circ} \mathrm{C}$ and $1000 \mathrm{~W} / \mathrm{m}^{2}$

\begin{tabular}{cccc}
\hline $\mathrm{I}_{\mathrm{mp}}$ & $7.61 \mathrm{~A}$ & $\mathrm{I}_{\mathrm{sc}}$ & $8.61 \mathrm{~A}$ \\
\hline $\mathrm{V}_{\mathrm{mp}}$ & $26.3 \mathrm{~V}$ & $\mathrm{~V}_{\mathrm{oc}}$ & $32.9 \mathrm{~V}$ \\
$\mathrm{P}_{\mathrm{mp}}$ & $200.143 \mathrm{~W}$ & $\mathrm{I}_{\mathrm{o}}$ & $9.82^{\wedge} 10^{\wedge}-8 \mathrm{~A}$ \\
$\mathrm{R}_{\mathrm{s}}$ & $415.405 \mathrm{ohm}$ & $\mathrm{R}_{\mathrm{p}}$ & $0.221 \mathrm{ohm}$ \\
\hline
\end{tabular}

Number of series units (Ns) is calculated as [13].

$$
\mathrm{N}_{\mathrm{s}}=\left(\frac{\mathrm{v}_{\mathrm{pv}}}{\mathrm{V}_{\mathrm{mp}}}\right)=\frac{700}{26.3}=26.62=27 \text { module }
$$

Number of parallel units is calculated as [13],

$$
\mathrm{N}_{\mathrm{p}}=\frac{\left(\mathrm{P}_{\mathrm{pv}} / \mathrm{V}_{\mathrm{pv}}\right)}{\mathrm{I}_{\mathrm{mp}}}=\frac{(21000 / 700)}{7.61}=3.94=4 \text { module }
$$

\subsection{DC-link voltage $\left(\mathbf{V}_{\mathrm{dc}}\right)$}

The minimum value of $V_{d c}$ must be kept more than double the maximum phase voltage. So, the value of DC link voltage is chosen as 700 volts.

$$
V_{d c}=\left(2 \sqrt{2} * V_{L L} / \sqrt{3} * m=(2 \sqrt{2} * 415) / \sqrt{3} * 1=677.69 \mathrm{~V}\right.
$$

\subsection{Inductor}

The value of interfacing inductance for phase leg is chosen as $2.5 \mathrm{mH}$.

$$
\mathrm{L}_{\mathrm{f}}=\left(\sqrt{3} \mathrm{~m} * \mathrm{~V}_{\mathrm{dc}}\right) /\left(12 \mathrm{j}_{\mathrm{s}} \mathrm{I}_{\mathrm{r}}\right)(\sqrt{3} * 1 * 700) /(12 * 1.2 * 10000 * .09 * 41.32)=2.26 \mathrm{mH}
$$

Where the grid current estimated as,

$$
\mathrm{I}=\left(\frac{\mathrm{P}_{\mathrm{pv}}}{\sqrt{3} * \mathrm{~V}_{\mathrm{n}}}\right)=\frac{21000}{1.732 * 415}=29.21 \mathrm{Amp}
$$

So, peak grid current, $\mathrm{I}_{\mathrm{p}}=\sqrt{2} * 29.21=41.31 \mathrm{Amp}$

\subsection{Ripple filter and DC link capacitor}

The chosen value of capacitor and resistance of the RC filter are $10 \mathrm{uF}, 5 \mathrm{ohm}$, respectively as taken from [13]. Here, $4600 u F$ as capacitance is chosen to stabilize Vdc during disturbances. The calculated value gives better result.

$$
\left(\mathrm{P}_{\mathrm{pv}} / \mathrm{V}_{\mathrm{dc}}\right) /\left(2 * \omega * \mathrm{~V}_{\mathrm{dcr}}\right)=(21000 / 700) /(2 * 314 * .02 * 700)=3412.2 \mathrm{uF}
$$

\section{CONTROL STRATEGY}

The proposed system utilizes two controls for different purposes. The incremental conductance method is to extract maximum irradiation from the PV system, and the adaptive based least mean sixth control is to produce gating pulses for the inverter. The significant equations used for the control algorithm are described as shown in.

$$
\begin{aligned}
& V_{\mathrm{sa}}=\frac{\left(\mathrm{V}_{\mathrm{sab}}+\mathrm{V}_{\mathrm{sbc}}\right)}{3} \\
& \mathrm{~V}_{\mathrm{sb}}=\frac{\left(-\mathrm{V}_{\mathrm{sab}}+\mathrm{V}_{\mathrm{sbc}}\right)}{3}
\end{aligned}
$$




$$
\begin{aligned}
& \mathrm{V}_{\mathrm{sc}}=\frac{\left(-\mathrm{V}_{\mathrm{sab}}-2 \mathrm{~V}_{\mathrm{sbc}}\right)}{3} \\
& \mathrm{~V}_{\mathrm{t}}=\sqrt{2 / 3\left(\mathrm{v}_{\mathrm{sa}}{ }^{2}+\mathrm{v}_{\mathrm{sb}}{ }^{2}+\mathrm{v}_{\mathrm{sc}}{ }^{2}\right)} \\
& \mathrm{x}_{\mathrm{pa}}=\frac{\mathrm{v}_{\mathrm{sa}}}{\mathrm{v}_{\mathrm{t}}}, \mathrm{x}_{\mathrm{pb}}=\frac{\mathrm{v}_{\mathrm{sb}}}{\mathrm{v}_{\mathrm{t}}}, \mathrm{x}_{\mathrm{pc}}=\frac{\mathrm{v}_{\mathrm{sc}}}{\mathrm{v}_{\mathrm{t}}} \\
& \left.\mathrm{e}_{\mathrm{a}}(\mathrm{n})=\mathrm{I}_{\mathrm{La}}(\mathrm{n})\right)-\mathrm{x}_{\mathrm{pa}}(\mathrm{n}) * \mathrm{~W}_{\mathrm{pa}}(\mathrm{n}) \\
& \left.\mathrm{e}_{\mathrm{b}}(\mathrm{n})=\mathrm{I}_{\mathrm{ba}}(\mathrm{n})\right)-\mathrm{x}_{\mathrm{pb}}(\mathrm{n}) * \mathrm{~W}_{\mathrm{pb}}(\mathrm{n}) \\
& \left.\mathrm{e}_{\mathrm{c}}(\mathrm{n})=\mathrm{I}_{\mathrm{La}}(\mathrm{n})\right)-\mathrm{x}_{\mathrm{pc}}(\mathrm{n}) * \mathrm{~W}_{\mathrm{pc}}(\mathrm{n}) \\
& W_{c}(n+1) W_{c}(n)+K_{p}\left\{V_{d c n}(n+1)-V_{d c n}(n)+K_{i} V_{d c n}(n+1)\right. \\
& \mathrm{V}_{\mathrm{dcn}}(\mathrm{n})=\mathrm{V}_{\mathrm{dc}}^{*}(\mathrm{n})-\mathrm{V}_{\mathrm{dc}}(\mathrm{n}) \\
& \mathrm{W}_{\mathrm{pv}}(\mathrm{n})=\frac{2 \mathrm{P}_{\mathrm{pv}}(\mathrm{n})}{3 \mathrm{~V}_{\mathrm{t}}} \\
& \mathrm{W}_{\mathrm{pa}}(\mathrm{n}+1)=\mathrm{W}_{\mathrm{pa}}(\mathrm{n})+\mu_{\mathrm{n}} \mathrm{x}_{\mathrm{pa}}(\mathrm{n}) *\left(\mathrm{e}_{\mathrm{a}}(\mathrm{n})\right)^{5} \\
& \mathrm{~W}_{\mathrm{pb}}(\mathrm{n}+1)=\mathrm{W}_{\mathrm{pb}}(\mathrm{n})+\mu_{\mathrm{n}} \mathrm{x}_{\mathrm{pb}}(\mathrm{n}) *\left(\mathrm{e}_{b}(n)\right)^{5} \\
& \mathrm{~W}_{\mathrm{pc}}(\mathrm{n}+1)=\mathrm{W}_{\mathrm{pc}}(\mathrm{n})+\mu_{\mathrm{n}} \mathrm{x}_{\mathrm{pc}}(\mathrm{n}) *\left(\mathrm{e}_{\mathrm{c}}(\mathrm{n})\right)^{5} \\
& \mathrm{~W}_{\mathrm{g}}=1 / 3\left(\mathrm{~W}_{\mathrm{pa}}+\mathrm{w}_{\mathrm{pb}}+\mathrm{W}_{\mathrm{pc}}\right) \\
& \mathrm{W}_{\mathrm{sp}}=\mathrm{W}_{\mathrm{g}}+\mathrm{W}_{\mathrm{c}}-\mathrm{W}_{\mathrm{pv}} \\
& \mathrm{i}_{\mathrm{sa}}{ }^{*}=\mathrm{W}_{\mathrm{sp}} * \mathrm{x}_{\mathrm{pa}} \\
& \mathrm{i}_{\mathrm{sb}}{ }^{*}=\mathrm{W}_{\mathrm{sp}} * \mathrm{x}_{\mathrm{pb}} \\
& \mathrm{i}_{\mathrm{sc}}{ }^{*}=\mathrm{W}_{\mathrm{sp}} * \mathrm{x}_{\mathrm{pc}}
\end{aligned}
$$

\section{RESULT AND DISCUSSION}

During normal operation, the solar irradiation level has been kept at $1000 \mathrm{~W} / \mathrm{m}^{2}$ and the temperature is kept at $25{ }^{\circ} \mathrm{C}$. The system remains stable during the operation shown in Figure 2 (a). Table 2 shows that the THD under normal operation is found satisfactory and conform to IEEE-519 standards. The solar insolation has been changed from $1000 \mathrm{~W} / \mathrm{m}^{2}$ to $600 \mathrm{~W} / \mathrm{m}^{2}$ at .03 second. However, the system remains stable during the condition. Figure 2 (b) shows the AC and DC waveforms under varying insolation conditions. Figure 2 (c) shows the waveforms when phase ' $a$ ' is disengaged through breaker for a time period from 0.03 second to 0.06 second. During the unbalancing load period, the grid current rises, and the compensating current goes a little bit down, but the active power transmission from PV array to the grid remains stable. The DC link voltage remains constant during the operation. The waveforms of average weight component $\left(\boldsymbol{W}_{\boldsymbol{g}}\right)$, fundamental weight component of phase 'a' $\left(\boldsymbol{W}_{\boldsymbol{p a}}\right)$, total weight component $\left(\boldsymbol{W}_{\boldsymbol{s p}}\right)$ and the feed-forward term $\left(\boldsymbol{W}_{\boldsymbol{p} v}\right)$ under unbalancing can be seen in Figure $2(\mathrm{~d})$. 

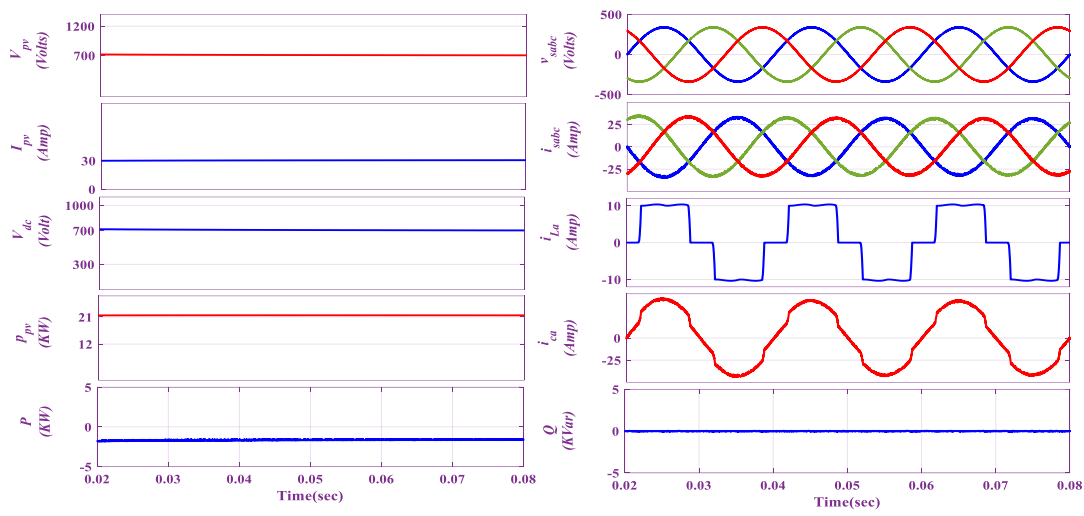

(a)
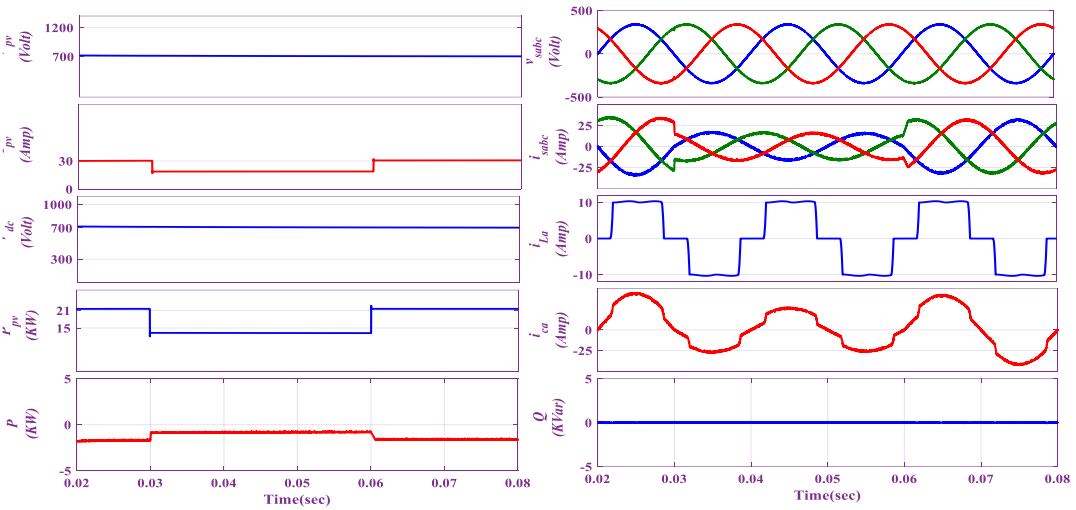

(b)
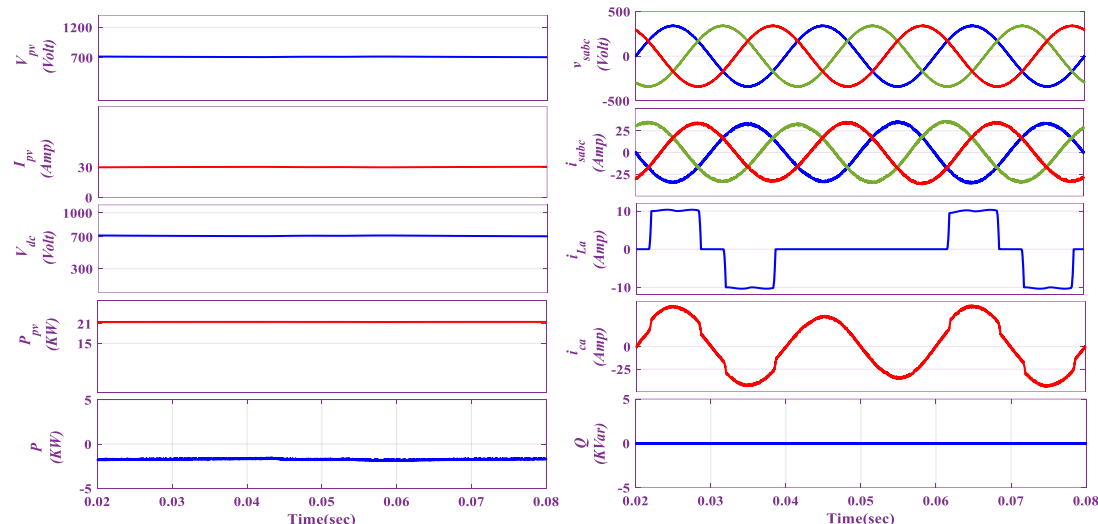

(c)

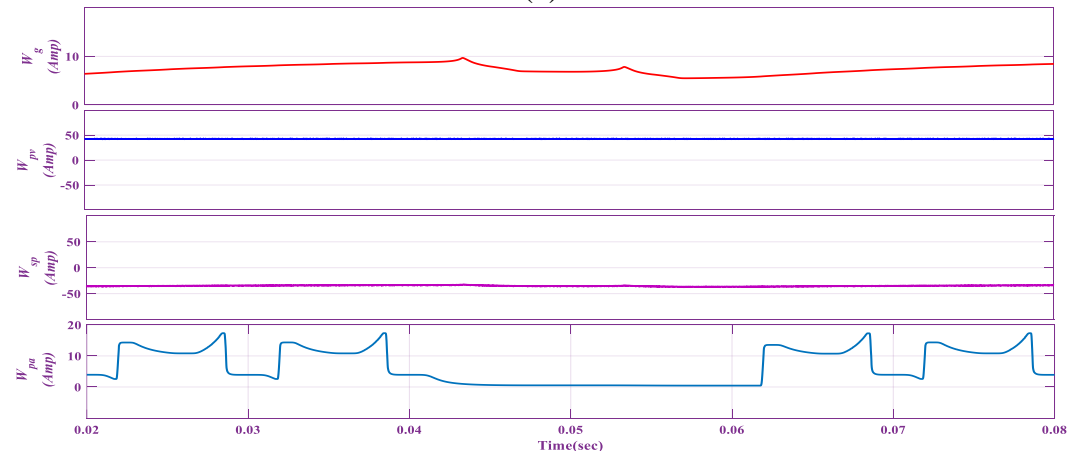

(d)

Figure 2. These figures are, (a) the system remains stable during the operation, (b) AC and DC waveforms under varying insolation conditions, (c) the waveforms a time period from 0.03 to 0.06 second, (d) the waveforms of average weight component under unbalancing 
Table 2. The THD under normal operation

\begin{tabular}{ccc}
\hline signal & Amplitude & THD \\
\hline Grid voltage $\left(v_{s a}\right)$ & $339.6 \mathrm{~V}$ & $1.12 \%$ \\
Grid current $\left(i_{s a}\right)$ & $32.11 \%$ & $3.16 \%$ \\
Load current $\left(i_{L a}\right)$ & $11.25 \mathrm{~A}$ & $28.61 \%$ \\
\hline
\end{tabular}

\section{COMPARITIVE STUDY}

The comparison made on the basis of the three main factors which are accuracy of extraction, signal oscillation and settling time. It is observed from the Figure 3 that the value of weight component $\left(W_{g}\right)$ extracted from the least mean sixth is more accurate in comparison to least mean fourth (LMF) control algorithm. In addition, oscillation in $W_{g}$ with least mean sixth is less when comparing it with the LMF control. Moreover, the settling time for the proposed control algorithm is less as compared to LMF control. The values of MSE and THD have been calculated under similar steady state condition. The MSE values for LMF and Least Mean Sixth cotrol are 24.9 and 17.7 respectively which means that the static error with the proposed new control approach is less than the LMF algorithm. Also, THD in grid currents are $4.47 \%$ and $3.16 \%$ respectively. Table 3 displays the comparative study between LMF control and proposed adaptive control.

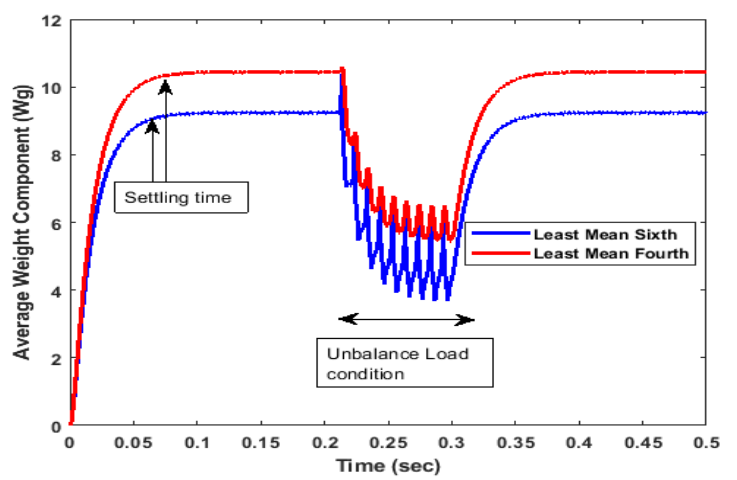

Figure 3. The value of weight component (W_g) extracted from the least mean sixth and least mean fourth

(LMF) control algorithm
Table 3. The comparative study between LMF control and proposed adaptive control

\begin{tabular}{|c|c|c|}
\hline Parameter & $\begin{array}{l}\text { Least Mean } \\
\text { Fourth Control }\end{array}$ & $\begin{array}{l}\text { Proposed Control } \\
\text { (least mean sixth) }\end{array}$ \\
\hline Filter & Adaptive type & Adaptive type \\
\hline Complexity & Lesser & Lesser \\
\hline $\begin{array}{l}\text { Degree of } \\
\text { optimization }\end{array}$ & $4^{\text {th }}$ order & $6^{\text {th }}$ order \\
\hline Accuracy & good & Better \\
\hline Static error & more & low \\
\hline MSE & 24.9 & 17.7 \\
\hline Sampling time & $1 \mu s$ & $1 \mu s$ \\
\hline Settling time & $.08 \mathrm{sec}$ & $.06 \mathrm{sec}$ \\
\hline THD & $4.47 \%$ & $3.16 \%$ \\
\hline Oscillations & less & less \\
\hline
\end{tabular}

\section{CONCLUSION}

The proposed system has been modeled for $21 \mathrm{KW}$ PV power and $5.8 \mathrm{KW}$ load. The system performance with the least mean sixth control algorithm and incremental conductance technique of MPPT has been used on MATLAB/Simulink. The novel control algorithm ensures rapid response to disturbances and fast convergence rate owing to the error increased to the fifth power. As a result, the bigger correction step has taken for larger errors. Moreover, the proposed system reduces the THD in grid currents and conforms to the IEEE-519 standard.

\section{REFERENCES}

[1] P. Bapaiah, "Power quality improvement by using DSTATCOM," International Journal of Emerging Trends in Electrical and Electronics, vol. 2, no. 4, pp. 1-12, 2013.

[2] I. Akhtar, M. Asim, R. K. Yadav, P. Agarwal, and S. Kirmani, "Design of effective grid-connected solar system," in International Conference on Inventive Computation Technologies Springer, Cham, vol. 98, pp. 606-614, August 2019, doi: 10.1007/978-3-030-33846-6 64.

[3] F. A. Khan, S. H. Saeed, M. Asim, S. Rahman, and P. R. Sarkar, "Cost optimization by adding SPV plant at load end in a grid connected system," 2018 International Conference on Computational and Characterization Techniques in Engineering \& Sciences (CCTES), 2018, pp. 65-70, doi: 10.1109/CCTES.2018.8674149.

[4] R. K. Agarwal, I. Hussain, and B. Singh, "LMF-based control algorithm for single stage three-phase grid integrated solar PV system," in IEEE Transactions on Sustainable Energy, vol. 7, no. 4, pp. 1379-1387, Oct. 2016, doi: 10.1109/TSTE.2016.2553181.

[5] B. Kandpal, K. P. Tomar, I. Hussain, and B. Singh, "Adaptive control of a grid-connected SPV system with DSTATCOM capabilities," 2017 4th IEEE Uttar Pradesh Section International Conference on Electrical, Computer and Electronics (UPCON), 2017, pp. 452-456, doi: 10.1109/UPCON.2017.8251090. 
[6] B. Singh, M. Kandpal, and I. Hussain, "Control of grid tied smart PV-DSTATCOM system using an adaptive technique," in IEEE Transactions on Smart Grid, vol. 9, no. 5, pp. 3986-3993, Sept. 2018, doi: 10.1109/TSG.2016.2645600.

[7] B. Singh, and J. Solanki, "A comparative study of control algorithms for DSTATCOM for load compensation," 2006 IEEE International Conference on Industrial Technology, 2006, pp. 1492-1497, doi: 10.1109/ICIT.2006.372413.

[8] D. Aiswarya, K. Ilango, and M. G. Nair, "A comparative performance analysis of PV grid interface STATCOM control algorithms," 2017 Innovations in Power and Advanced Computing Technologies (i-PACT), 2017, pp. 1-7, doi: 10.1109/IPACT.2017.8245213.

[9] S. Shivam, I. Hussain, and B. Singh, "Real-time implementation of SPV system with DSTATCOM capabilities in three-phase four-wire distribution system," IET Generation Transmission Distribution, vol. 11, no. 2, pp. 495-503, January 2017, doi: 10.1049/iet-gtd.2016.1032.

[10] H. J. Mohamed, M. A. Abdulsalam, F. A. Mansur, M. Anwar, and M. Nizam, "Design and simulation studies of DSTATCOM for mitigatingvoltage sag problem by using fuzzy inference system, and proportional integral based on controlled application," International Journal of Advanced Research in Electrical, Electronics and Instrumentation Engineering, vol. 3, no. 8, 2014.

[11] R. K. Agarwal, I. Hussain, and B. Singh, "Implementation of LLMF control algorithm for three-phase grid-tied SPV-DSTATCOM system," in IEEE Transactions on Industrial Electronics, vol. 64, no. 9, pp. 7414-7424, Sept. 2017, doi: 10.1109/TIE.2016.2630659.

[12] G. Varshney, D. S. Chauhan, and M. P. Dave, "Performance analysis of photovoltaic based DSTATCOM using SRF and IRP control theory1," 2015 1st International Conference on Next Generation Computing Technologies (NGCT), 2015, pp. 779-783, doi: 10.1109/NGCT.2015.7375226.

[13] B. Singh, A. Chandra, and K. Al-Haddad, "Active shunt compensation," Power Qual. Probl. Mitig. Tech., pp. 96169, December 2014, doi: 10.1002/9781118922064.ch04.

[14] N. Kumar, B. Singh, and B. K. Panigrahi, "LLMLF-based control approach and LPO MPPT technique for improving performance of a multifunctional three-phase two-stage grid integrated PV system," in IEEE Transactions on Sustainable Energy, vol. 11, no. 1, pp. 371-380, Jan. 2020, doi: 10.1109/TSTE.2019.2891558.

[15] N. Zaveri, A. Mehta, and A. Chudasama, "Performance analysis of various SRF methods in three phase shunt active filters," 2009 International Conference on Industrial and Information Systems (ICIIS), 2009, pp. 442-447, doi: 10.1109/ICIINFS.2009.5429819.

[16] R. K. Agarwal, I. Hussain, and B. Singh, "Integration of single-stage SPV generation to three-phase distribution grid using a variable step size LMS control technique," 2016 IEEE 1st International Conference on Power Electronics, Intelligent Control and Energy Systems (ICPEICES), 2016, pp. 1-6, doi: 10.1109/ICPEICES.2016.7853060.

[17] S. Pradhan, I. Hussain, B. Singh, and B. K. Panigrahi, "Modified VSS-LMS-based adaptive control for improving the performance of a single-stage PV-integrated grid system," IET Science, Measurement, and Technology, vol. 11, no. 4, pp. 388-399, July 2017, doi:10.1049/iet-smt.2016.0351.

[18] K. Hosseini, A. Montazeri, H. Alikhanian, and M. H. Kahaei, "New classes of LMS and LMF adaptive algorithms," 2008 3rd International Conference on Information and Communication Technologies: From Theory to Applications, 2008, pp. 1-5, doi: 10.1109/ICTTA.2008.4530045.

[19] M. Mangaraj, T. Penthia, and A. K. Panda, "Implementation of sparse LMS control algorithm in DSTATCOM," 2016 National Power Systems Conference (NPSC), 2016, pp. 1-6, doi: 10.1109/NPSC.2016.7858951.

[20] D. J. Park, B. E. Jun, and J. H. Kim, "Fast tracking RLS algorithm using novel variable forgetting factor with unity zone," Electronics Letters, vol. 27, no. 23, pp. 2150-2151, 1991.

[21] M. Badoni, A. Singh, and B. Singh, "Variable forgetting factor recursive least square control algorithm for DSTATCOM," IEEE Transactions on Power Delivery, vol. 30, no. 5, pp. 2353-2361, Oct. 2015, doi: 10.1109/TPWRD.2015.2422139.

[22] S. R. Arya, and B. Singh, "Performance of DSTATCOM using leaky LMS control algorithm," IEEE Journal of Emerging and Selected Topics in Power Electronics, vol. 1, no. 2, pp. 104-113, 2013, doi: 10.1109/JESTPE.2013.2266372.

[23] R. Rajagopal, K Palanisamy, and S. Paramasivam, "Comparative performance of normalized LMS and variable step size LMS based control for shunt active filtering," 2019 9th International Conference on Advances in Computing, 2019, doi: 10.1109/ICACC48162.2019.8986184.

[24] K. Keshavani, J. Joshi, V. Trivedi, and M. Bhavsar, "Modelling and simulation of photovoltaic array using matlab/simulink," IJEDR, vol. 2, no. 4, pp. 3742-3751, 2014.

[25] M. G. Villalva, J. R. Gazoli, and E. R. Filho, "Modeling and circuit-based simulation of photovoltaic arrays," 2009 Brazilian Power Electronics Conference, 2009, pp. 1244-1254, doi: 10.1109/COBEP.2009.5347680. 


\section{BIOGRAPHIES OF AUTHORS}

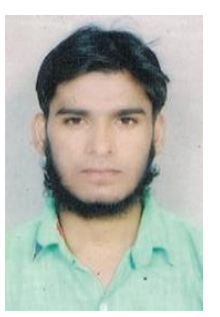

Touheed Khan has completed his Bachelor degree (Electrical Engg.) with honours from Dr. A P J Abdul Kalam Technical University Lucknow, India \& M. Tech degree with honours from Integral University Lucknow, India in the year 2016 and 2020 respectively. His research area includes Control system and Renewable Energy. He has published many research papers in national and international journals. He is currently working as a Laboratory Instructor in Electrical Engineering Department, Integral University, Lucknow, India.

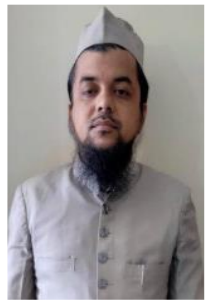

Mohammed Asim is currently working as a Assistant Professor at Integral University, Lucknow since 2013. He has got more than 10 years of teaching experience. He has completed his B.Tech and M.Tech from Aligarh Muslim University in the year 2007 and 2009 respectively. Later on he has done his PHD from Integral University Lucknow in the year 2017.His research area include Power Electronics and Renewable Energy. He has got a patent and number of research paper. He is currently working on a project titled "An efficient Solar PV based hybrid multi output converter for standalone application" sponsored by National Project Implementation Unit. He has received best paper award in two International Conference SIGMA and ICRP in the year 2018 and 2020 respectively.

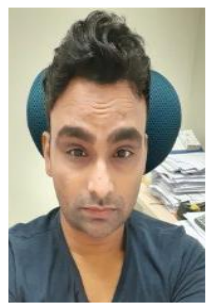

Mohammad Saood Manzar, He is a lecturer in Environmental Engineering Department of Imam Abdurrahman Bin Faisal, Dammam, Kingdom of Saudi Arabia since 2014. Previously, he served as an Assistant Professor for about 3-years in SRM University, Ghaziabad (India). He has over 19 research publications, and more than 5 presentations and invited talks in conferences and seminars. He has hands on a number of areas and instruments like high-performance liquid chromatography (HPLC) and atomic absorption spectroscopy (AAS). I am actively involved in different wastewater treatment projects of Environmental Engineering Department such as synthesis, characterization of different kinds of waste, polyamine resin composites, modified bentonite, modified graphene, layered double hydroxides composites, and their application in waste water treatment.

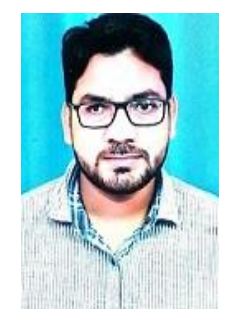

Md. Ibrahim is currently working as a lecturer at the University polytechnic Integral University Lucknow, India. He completed his bachelor \& master degree in Electrical Engineering from Aligarh Muslim University, Aligarh, India. He completed his PhD in 2020 from Integral University Lcknow, India. His research area includes solar photovoltaic systems, Control system, Micro-grid and Renewable Energy. He has published many research papers in National and International Journals.

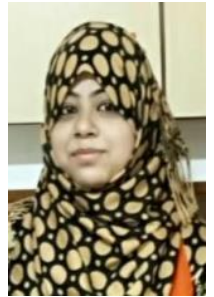

Shaikh Sadaf Afzal Ahmed My aim is to develop myself as a successful person personally and professionally giving my best towards the organization. I have done Bachelors in Computer Science from University of Mumbai in 2016. Previously, I served as an Assistant Professor for about 2-years in A.E. kalsekar degree college (India) and taught courses related to Computer Engineering (undergraduate Level). I have published two papers in International and National Journal. 